\title{
A New Discourse Out of a Dark Atmosphere: Critical Discourse Analysis of Iran's Eleventh Presidential Election
}

\author{
Anna Parvin \\ Studied MA in Linguistics at University of Tehran \\ Lecturer in University of Applied Science and Technology in Iran \\ E-mail address: Anna.parvin66@gmail.com
}

Keywords: language, CDA, election, signifier and signified, articulation.

\begin{abstract}
This paper tries to indicate how the candidates of Iran's eleventh presidential election attempted to rise to power by the means of language. In this analysis, the discourse theory of Laclau and Mouffe is applied. The candidates tried to win the battlefield of election by creating exclusion borders and excluding their rivals. Critical discourse analysis is a methodology that can reveal ideological purposes behind the political discourses to reflect the hidden Realities. The study of the debates between presidential candidates shows that Hassan Rouhani was elected because he could exclude other discourses resulting from the rising sociopolitical crisis. Nevertheless, He could not articulate his floating signifiers and his discourse was not hegemonic.
\end{abstract}

\section{INTRODUCTION}

Language is like a mask on the face of reality. By analyzing the language, we can remove this mask and reveal the hidden ideas. Politicians use language as a mask in order to achieve their goal, which is of course winning people's hearts and minds. Moreover, they bridge social, political and economic gaps with signs and language instead of reality. These gaps will never be filled in reality, but rather in fantasy. Both Politicians and people know the fact that these gaps will remain in place, but they delude themselves into believing that these gaps can be filled. "There is nothing to guide or constrain our thoughts and feelings, so we can do or say whatever we feel like" (Hicks 2:2004). The relation between language and power is highlighted in election more than ever. Election is a battleground for the candidates' discourses. A candidate who is more powerful and flexible in his outlooks can win the election. In the age of enlightenment, rulers were not afraid of death, while in the postmodern age they are not afraid of language. The power of postmodernism makes us think and choose the way we desire in a world that is represented to us. Discourses of politicians are derived from the needs of the people or the intentions of those who are in power. Eleventh Presidential Election in Iran is one of the most challenging subjects in the country's social and political arena. This election was held in a situation where the country had plunged into the abyss of economic ruin. On the one hand, economic problems resulted from stagnation. On the other hand, Iran's disputed nuclear program resulted in inflammatory speeches in international arena, and brought about the widespread economic sanctions against the country. The subsequent political tensions did a lot of damage to the political and economic life of the people in Iran. In this crisis, the election campaign turned into a fierce competition among presidential candidates. Candidates tried to match their words to reality in order to win the election. They come to this arena with different political visions and slogans. One campaigner used the catch phrase "Alliance for Progress", while the other one came with a key, a symbol to open the lock of difficulties. In other words, he showed his ability to solve problems. Finally, Hassan Rouhani won the election with the slogan "Contrivance and hope". Thereby the government of Contrivance and hope prevailed in the war of discourses.

\section{RESEARCH QUESTION:}

The question that is raised in this study asks about how Hassan Rouhani, the current president, managed to defeat his rivals in the bleak atmosphere of Iran's politics, during the tenth 
presidential election? More specifically, the study tries to indicate whether Rouhani's discourse was hegemonic in this political campaign or not.

\section{THEORETICAL FRAMEWORK:}

The theoretical approach used in this study is Laclau and Mouffe's discourse theory. This is a combinational theory that stems from Saussurian structural linguistics and the ideas of a number of figures like Derrida, Foucault, Marx, Gramsci, Lacan, Heidegger, Rorty and Wittgenstein. This theory considers a central role for understanding social phenomena and relationships and the way in which they change within the political process of conflicts among the forces of otherness for the formation of social meaning. The main area of concern in this discourse theory is people's ideas and perceptions of themselves in communities. People's views about the world are the products of discourses. This theory believes that objects and phenomena can be meaningful just through the valve of hegemonic discourse on society. Glledhill explains:

Laclau's main argument is that social identities are always discursive constructions in Foucault's sense: social subjects and their practices are constructed through discourses, on ethnicity, gender, and indeed politics. In laclau's view hegemony rests on those constructions.(Laclau and Mouffe, 2000:191).

In any political discourse which is formed based on Laclau and Mouffe's theory, a series of signs are placed along each other in an equivalence chain by which they achieve meaning. Therefore, the signs of the discourse achieve their meanings through links with each other. One of the most important hypotheses in the discourse theory is diversity and inherent disorganization of society. Through the concepts of equivalence chain and logic of difference (otherness), this diversity is explained. Thus, in an articulation, the main signs of the semantic chain are combined with other signs and are put against "the other" that seems to threaten them. This type of arrangement is called the discourse theory of equivalence chain. Discourses overlap these differences through this equivalence chain. Here, elements lose their heterogeneous attributes and conflicting meanings and are solved in a syntax which creates a specific discourse.

It is important to note that the different properties of the various elements and signs in an equivalence chain can never lead to complete removal of these differences and it is always possible to face the appearance of difference and diversity and removal of some elements from the equivalence chain. Therefore, the logic of equivalence can be considered as the simplifying logic of a political atmosphere (Dabiri Mehr 1286:2014).

Logic of differences is one of the concepts inferred from otherness. This logic refers to plurality trait of society and focuses on diversity between the social forces. It attempts to emphasize on distinctions and variants, differences in social domain and consequently, uproots the current equivalence chain. Here hostility and otherness will become more outstanding (Dabiri Mehr $33: 2013)$.

\section{Iran's Political Atmosphere}

There are fundamental similarities and differences between the critical discourse analyses in the discourse atmosphere of election, and also in non-electoral atmospheres, like revolutions, coups and other ways of rising to power. In the atmosphere of revolution or coup a much greater role is assigned to charisma, ideals and dreams, than in electoral atmosphere, where the issues are presented with a more realistic precision and delicacy. One could trace this level of realism to the relative stability of discourse in Islamic Republic, which is formed around the concept of spiritual leadership, which must be legally acknowledged by all other discourses. Otherwise these discourses will not be allowed to participate in any hegemonic processes or political activities.

On the one hand, in order to maintain political stability, to avoid anarchy, and to make room for the activities of small discourses, Iran's political atmosphere creates a number of discourses that are not essentially different from each other. On the other hand, in order to be prepared for a power 
struggle, these discourses have to appear distinct from one another. Therefore, for a short period during the elections, political bargaining, which is one of the customary methods in Iran's political milieu, assumes the qualities of a discourse, and in this way it attempts to find, create, foreground and exclude meanings. This happens in spite of the fact that, in other historical periods, the need for such discourses is not really felt. However, the main factor that created a wide rift among the 2013 election rivals, and led to a serious campaign in that election, was the rise of extremism in foreign and economic policies. In fact, the former administration deepened the old rift between extremism and moderation, which resulted in a widespread division among the forces within the establishment. Not only did this division drove these forces further apart, but also it compelled them to line up against each other. Moderation and extremism have gone through ups and downs in the postrevolutionary history of the country; at some stage in history they could be considered as the old residues that have, once again, been brought to surface.

This article is not going to deal with the rift between moderation and extremism, but it attempts to elaborate on the contradictions in discourse that arise from such a rift. The rather insignificant split between extremism and moderation, which has stemmed from discourses, and which has always been controlled by the Islamic Republic, by software and hardware means, could sometimes give rise to challenges and major crises facing the formation and elimination of identities in the power struggles of the Islamic Republic, as witnessed in the 2013 and 2009 elections, or even such historical incidents as the elimination of Bazargan and Banisadr administrations.

Accordingly, we analyze the manifestation of the new arrangements of the forces participating in Iran's political arenas including the 2013 election, and then we assess the discoursing challenges in the metaphorical atmosphere of the eleventh presidential election. In this respect, we will apply Laclau and Mouffe's approach in order to examine the televised debates of the election.

\subsection{The Arrangement of the Forces Participating in Iran's Political Landscape}

As it was indicated, most of the developments in this historical phase are rooted in the two discourses of moderation and extremism. These two discourses are themselves based on the elements of tradition and modernity, which are rooted in the major developments of the Islamic Revolution. Thereby, the arrangement of the sub-discourses in Iran's sociopolitical milieu could be divided into two major groups:

1. A more pragmatic group which is guided by economic and political realities, and whose debates revolve around the improvement of economic condition, individual freedoms, and civil society. As opposed to the other group, this group relies on concrete realities, and follows the discourse of development and reform.

2. The other group can be dubbed as the group of idealists and extremists who emphasize the ideals and values. Their debates center on independence, religion, salvation, values and resistance. This group accentuates the importance of minds. The rise of this mentality in Iran's political process could be attributed to the political inclinations of the ninth and tenth administrations, which constituted a new political body that was not actively present in the course of revolution, and involved a new generation of political officials in the Islamic Republic. This group is comprised of a majority of the traditional conservatives, the followers of Ayatollah Mesbah (Resistance Front), Hojatieh Institute, Abadgaran Coallition, and the United Front of the Traditional Conservatives. As Irannezhad contends, "It appears that religious misgivings and cultural conditions of the country are among the most important causes of debates among the promoters of the Islamic conservatism discourse" (Irannezhad 2012:100).

Each one of these two groups can be divided on the basis of modern and traditional discourses. The roots of traditional and modern discourses could be regarded as the most significant issues of concern and sociopolitical challenges which have been there in Iran's sociopolitical atmosphere since the early Qajar era, and have always been the two basic contradictory driving forces for social upheavals in the country (Soltany, 2012:136). As indicated in Bashirieh's Introduction to Iran's Political Sociology, the rise of capitalism and the accumulation of capitals led to the creation of 
these two social forces: "Pahlavi Government's attempt to confront the traditional forces such as the clergy, nomads, and the bazar merchants, and its support of the developments that resulted in the creation of modern forces, did in fact divide the Iranian society into two major camps and left the modern and traditional forces on a collision course with each other (Bashirieh, as quoted in Soltany).

As a consequence, we are facing two stimulating forces in Iran's political history, two forces in opposition to each other, which formed the sub-discourses of the Islamic Republic. The first one, the Pahlavi government did, in the long run, reinforce the struggle between tradition and modernity. The second one, represented by such figures as Ahmadinejad, did, in a short term process, raise the dispute between the hardliners and moderates. Therefore the clergy and the bazar merchants constituted a major social backbone of the traditionalists after the revolution. Although they were regarded as the first generation of the revolutionaries, their economic and political reservations forced them to take a more conservative and objective stance on political issues. However, the second group that was comprised of the commanders of Revolutionary Guards, bureaucrats, university professors and war veterans, did neither have any roots in the revolution, nor did it rely on the traditional economy in their economic outlooks. Most of them were among the educated people whose incomes were secured by other resources. Although the economic policy of the ninth administration, such as opening chain stores etc., could not keep the hands of bazar traditionalists off the Iranian economy, but it managed to intensify the dispute to a higher degree. In this situation two groups that were still on the train of revolution, faced off in the 2013 presidential election. One group that had survived after the war, and consisted of the Participation Front, the Mujahidin of the Islamic Revolution and the Hojatieh Institute, had been forced to get off the train. They were cast aside on charges of sedition and deviation from the path of revolution. Of course this manner of dividing the political forces might, to a great extent, be considered as something abstract, because in the absence of political parties, civil society, and free press, the political forces are shaped rather by power structure than by the actual rifts within the society. That is the reason why these forces can once again be articulated around the signifier of the spiritual leadership, in spite of all the disputes and disagreements.

\subsection{Discourse Challenges in the Arena of the Eleventh Presidential Election}

One can certainly argue that the biggest discourse challenge is the very lack of discourse, and in the best situation the groups, currents and camps could express themselves within the framework of "defensive discourse ${ }^{1}$ ". And no discourse has so far been able to turn into a hegemonic discourse by the means of articulation. The sub-discourses in the system have accepted the spiritual leadership either as a law or on the basis of its ideals. Any kind of activity within the system depends on the acceptance of the leadership as the central core. However, since the discourses, as indicated in Laclau and Mouffe's theory, are divided into two groups, us and them, their world and their outlook are also divided on the basis of two predicates. Thereby, the nodal point of "value" and "key" (solution) shape their world. The nodal point becomes hegemonic based on the articulation of each of the two groups. The group that sees the key in the realities of economic and foreign policies are the moderates who try to turn this key into a hegemony. The other group regards the ideals and values as the nodal point. They are the extremists or hardliners who try to make these ideals and values hegemonic.

Articulation is not the factor that constitutes the metaphorical atmosphere, since none of the groups in the arena of elections have the required individual charisma for that articulation. Nodal point is the only element that makes it possible for the sub-discourses to emerge and prevail, and that is not due to their grandeur and metaphorical illusion, but because of the critical atmosphere that has been created by the economic sanctions and the difficulties in people's livelihoods. The atmosphere that was formed after the ninth and tenth Iranian administrations had made the discourses more than

1 Every discourse is threatened by a number of anti-discourse elements. In order to neutralize these threats and to establish itself, every discourse needs to create a safe haven in which it can protect its very existence. This situation which allows for a discourse to apply defensive tactics is called "defensive discourse". 
ever floating. Due to the critical condition of people's livelihoods, the subjects, who are floating in the discourses, are inclined to go in search of miraculous solutions. In times of peace and prosperity talking about sensibility and contrivance seems to be easy, but in a critical situation, sensibility is more than ever replaced by illusion. Because of this critical situation, the subjects are, more than any other time, prepared to believe in the signifier that claims to be able to rescue them. They do not think about the practicality of the signifiers, but rather about the very signifiers that are displayed before them. Those sub-discourses that are outside the system and cannot put their signifiers into practice, and those agents who are claiming that the situation is not critical, will inevitably be marginalized. In other words, the contrast here is between two entirely different worlds. One group tries to show that the world is in a critical condition and they have the solution in their hands, and the other group insists on the normal condition of the world. In a critical condition the living champion talks about economy and the issues that are relevant to it, such as psychological and social security, foreign policy, reducing the tensions etc. Ideals and values become the subcategories of economy.

The metaphorical atmosphere that became the dominant spirit in the 2013 election, was to save the country from the threat of war and to improve people's livelihood, which had deteriorated because of the hardline stance of the former administration. Voting for each one of the moderate candidates was not seen as a Yes vote to them, but an outright No to the status quo. Therefore, winning this challenge was not the result of articulation, foregrounding and creation of meaning, but an outcome of excluding the others, specifically the exclusion of nodal points in extremists' discourse. This exclusion was expressed more strongly than before. The subjects were agonized by the castrated and floating discourses, and were open to any signifier that could exclude extremism. Accordingly, any discourse that was able to implement its nodal point, and enjoyed a mentality, affiliation and historical record that was distinguished from that of the former administration, could naturally be the winner.

The nodal point of "values" confronts the "keys". One can even deduce the contrast between subjectivity and objectivity from its appearance. Emphasizing the signifiers of contrivance, responsibility, lowering the tensions, social security, individual liberty, transparency, economic improvement, and civil rights are all objective issues. Meanwhile the signifiers of value, revolutionary conduct, independence, and social justice, are subjective issues. The signifier of "values" is too distant from the signifier of "key", and tries to make all other signifiers hegemonic within the limits of what actually "exists". That is in spite of the efforts by the signifier of "key" to open new windows. It is clear that each of the two groups tries to foreground itself and exclude the other. The first one engages in a software power struggle to connect the other one to the former administration, or to the foreign powers such as Russia and China-they have a rather negative image in the minds of Iranian people - and blames the sanctions on their performance. The second group tries to exclude the first one by associating them with the reform movement and the so called sedition, and making use of foreign signifiers that are affiliated with the west.

Based on the two major signifiers of extremists (illusionists) and moderates (realists), and the two traditional and modern discourses, one can reach some fundamental classifications. As it was stated before, the discourses of the 2013 presidential candidates could be generally categorized as follows:

1. Moderation discourse with the nodal point of "key"

2. Extremist discourse with the nodal point of "values"

The first one relies on public outlook, and the second one invokes the ideals, values, and majestic resistance. Articulation, as Laclau and Mouffe contend, "is an action that creates a link between various elements, and in the course of these elements the action of articulation changes" (Laclau and Mouffe, 2013, 171). Based on this definition, we have to take into consideration the processes of exclusion and foregrounding, and the methods of attracting the floating elements that are applied in the course of these processes. Therefore every discourse attempts to turn the floating elements into a moment, and endow it with a meaning around its nodal point. As Laclau and Mouffe recount, "all identities are linked to relations, and all relations have an essential attribute" (Ibid: 172). 
Extremism embraces all the discourses that emphasize the subjective issues. Subjective issues include revolutionary approach, values, resistance, spiritual leadership, logic, right and wrong, and social justice. It reveals a world where we are capable, and our capabilities can themselves be regarded as a model irrespective of such issues as economy, political or military power, and people's right to choose. In the hardline mentality there is no place for moderation, for there is a sharp contrast between right and wrong without any middle path. Since morality and values constitute the main outlook and viewpoint in the discourse of extremism, everything is divided into "us" and "them". They are either our friends or our enemies, and in this game there will be only winners and losers. This type of discourse is intuitive and all-encompassing. In the discourse of traditional conservatism the leadership, as a symbol of unity, plays a vital role, and acts as a safety belt that prevents the society from falling in the mire of faithlessness (Bashirieh, 1999, 76-7).

The concept of "moderate" entails all the discourses that emphasize the objective issues. Objective issues include constructive compromise with the world, liberty bound by responsibility, social justice, civil rights, security and contrivance. It reflects a world in which the level of our abilities is determined by the objective realities. As it appears, the discourse of the moderates provides a more realistic picture of the internal and external issues, because the outlook of morals and values is replaced by an economic and profit-based outlook. In this discourse one can find a middle course, because one believes that for everything there is room for bargaining. There is no such thing as absolute zero, and one can come to a win-win situation in the game of politics. The debate here is not over right or wrong, but over the interests.

\section{AN ANALYSIS OF THE TV DEBATES IN THE ELEVENTH PRESIDENTIAL ELECTION}

In this section, we will look at the televised election debates from economic, political and cultural perspectives. We have selected some areas to indicate how the candidates in this political contest exclude the opposite side to articulate their own nodal point, and to dismantle the nodal point of their rivals.

\subsection{Economic TV Debate}

In his TV debate, Saeed Jalili, one of the hardline candidates, describes the objective of economy as such: "We should have an economy that is based on the discourse of revolution and the system, because people believe that this discourse can bring about progress for us". The signifiers of "revolution" and "system" are the signifiers of values, which are intuitively attributed to the public belief. In another place he says "we should prioritize justice over progress". Jalili's image of justice is based on the nodal point of values and is totally subjective. In fact, when justice comes before progress, it becomes the distribution of poverty. When Jalili does not prioritize the basis for progress over justice, it is because justice is a subjective and value concept. Therefore, his definition of justice is totally different than Rouhani's definition, which is based on the signifier of key. Rouhani describes justice as thus:

With respect to justice, we should point to rent-seeking and corruption, because unfortunately these are the problems that we have faced more frequently in the last few years. Also the supreme leader has emphatically insisted on tackling the economic corruption... justice means equal opportunity for all people, Iranian citizens, from different ethnicities and religions. Therefore, this opportunity should be created. ${ }^{2}$

The emphasis on the signifier of rent-seeking and corruption indicates equal opportunities for people to have access to the country's resources, which is offered by Rouhani to the public, in view of the discourse of key and solution. Saeed Jalili, from the extremist discourse, tries to employ the signifier of value to provide a definition of justice which is different from the one provided by the

\footnotetext{
${ }^{2}$ In this article the quoted statements of the candidates are from the recorded election debates available on www.aparat.com
} 
moderates, and in this way, he tries to foreground himself. He excludes the moderates whose goal is the country's development and growth, and claims that they are far from the values. This is in spite of Rouhani's effort to highlight the realities of the country's economy to show that Jalili and his sympathizers are actually fueling the corruption, and try to deceive people in the name of values. He accuses Jalili of not caring about social justice, and claims that he is exploiting the signifier of values to rise to power. In the face of every action that challenges the authority of the hardliners, they make use of the element of values to show that this action is a threat to the values. On the contrary, the moderates exclude any action that threatens the concepts of "key" and "solution" in their discourse, and in their view values are opposed to the solution.

\subsection{Political TV Debate}

The signifier of freedom is a floating signifier which is closer to becoming "moment" in moderates' discourse, while it gets closer to becoming "element" in the extremists' discourse. That is because in the moderates' discourse the people are the actual addressees, and all of them can enjoy that freedom. However, the extremists emphasize the signifier of values, and look at the people from the perspective of morality, right and wrong. In their view, those who do not believe in the signifier of values are considered as enemy, evil, and wrong. For example, in his political TV debate, Ghalibaf, one of the hardliners, tries to dismantle the moderates' floating signifier of freedom, and makes it hegemonic using the nodal point of values. In this respect, he says:

I remember the 2003 incidents when I was the commander of the police force. At that time you (Rouhani) were the secretary of the Supreme National Security Council. You remember, the students used to hold the anniversary of Tir $18^{\text {th }}$ police raid on the dormitories. In a meeting with you I stated my belief that the Unity Consolidation Bureau (a student organization) is about to hold a ceremony on Tir $18^{\text {th }}$. I remember you said, "You are looking for trouble. Leave it off, what kind of authorization do you want to give? There, I believed that the students should be able state their views, but within the framework of law.

The constant use of the signifier of freedom illuminates Ghalibaf's effort to take the signifier of freedom away from the moderates, and to dismantle it in order to foreground it for himself. Meanwhile Rouhani tried to use the signifier of garrison and military, to secure the votes in those areas where Ghalibaf tried to win the majority. He managed to turn the element of freedom into the moment, using the signifier of jurist. He says:

I have always followed the line of moderation... My path is always clear. I have never acted or thought according to the garrison rules. I am among those who have studied the law. I am not a colonel, I am a jurist.

One may regard foreign policy as one of the most crucial subjects in the election debates. During the four years of Ahmadinejad's presidency it was a signifier that was regarded by many of his opponents as a major cause of the difficulties and crises. Since the time that the nuclear issue turned into a crisis, the opponents of the hardliners highlighted such issues as the sanctions, difficulties, extremism and overemphasis on values, in order to dismantle it. This is why they believe that Iran is in a critical condition, whereas the extremists do still stress the importance of the signifier of values. They claim there is no particular problem, nothing has happened, and the economy should be sacrificed for the sake of values. For instance, Ghalibaf introduces his entire view of the foreign policy in this way:

The foreign policy should guarantee our national interest, national security, national identity, religious identity, and our revolutionary identity. This is the mission that is appointed for our foreign policy and diplomacy. As in other areas, our foreign policy should not move away from our Prospect Plan.

The link between our national interest and security, and also our national, religious and revolutionary identities illustrates the two subjective and objective identities. On the one hand his discourse relies on the signifier of values, and on the other hand it relies on the signifier of people. In view of the fact that he insists more on the signifier of values, one can consider him as an 
extremist, while at the same time he is also deemed modern. In his political approach he is a hardliner, but when it comes to economy and foreign policy he is rather moderate. In other place, Jalili criticizes Velayati's line of approach which is more moderate than that of his own, and asserts:

Did you say you will make peace with the world and we should not be hostile towards others? I don't understand it. The debate over international relations is not about peace and hostility, it is not a personal issue. It is all about the interests. If our interests are not in line with the interest of others, we must defend our rights.

Jalili points out the national interests which is a floating signifier of the moderates, and tries to dismantle it by referring to the nodal point of values. Velayati also tries to make use of the signifiers of solidarity, contrivance and bargaining that are the major signifiers of the moderates, who have gathered around the signifier of solution. In this way he tries to dismantle Jalili's discourse, so that he can portray himself as a moderate traditionalist and gain more votes. He says:

Traditional conservatism does not mean that one has to be inflexible. With respect to the national interests we should be able to apply diplomacy in the best possible manner. Diplomacy is not only about obstinacy and displaying violence. It is a kind of deal, a compromise...

As it appears, Velayati undermines the extremist camp's emphasis on values, using the signifiers of contrivance, national interests and basically solution. In Velayati's moderate discourse the signifier of key is placed against the extremists' signifier of values. In other place Ghalibaf employs such signifiers of values as martyrdom, the combatants of Iran-Iraq war, and the war itself dismantle the moderates' nodal point of key and solution, and accordingly to foreground his discourse and make it hegemonic. He addresses Velayati and says:

There is a reciprocal relationship between the combatants and military movements on the one hand, and politics on the other hand. I believe during your 16-year tenure (as foreign minister), you always made a one-sided use of the capacities of the combatants and their sacrifices, in the interest of the foreign policy. The foreign policy never came to the assistance of the war combatants.

Nonpartisan approach is one of those approaches that have always been pursued in elections. The so called third line forces or the third force try to foreground the rift between the two powerful and dominant discourses in the election. They put the blame on these discourses in order to introduce their camp as a new force that is devoid of any flaws. In this election Ghalibaf, Rezaii, and Gharazi tried to apply this strategy. They stressed the nonpartisan signifiers to disapprove of those who had taken a partisan approach in the course of the election, and in this manner, they magnified their own signifier. For instance, Rezaii says:

Fortunately I have not participated in any of these disputes, and can have a more precise judgment of the situation. I was neither in Mr. Khatami's team to dismiss the Traditional Conservatives, nor in Mr. Ahmadinejad's team to remove the Reformists. I do not approve of any of these two camps. My criteria in recruiting capable forces are competence and loyalty to the system.

Or Ghalibaf says:

Talking about what the Traditional Conservatives and Reformists have done so far will only lead to discord, whereas people's concern is something else...

In fact he tries to dismiss both sides in order to set forth his own nodal point. Gharazi also says:

The governance makes it necessary to retain the people within the orbit of revolution. As long as we want to divide the country into political groups, it is opposed to the revolution and the dignity of the leadership.

The third way signifier's chances of winning the election are slim. That is because a fundamental exclusion of a major discourse requires an equal foregrounding of an alternative discourse, whereas a halfway exclusion would not leave any chances. 


\subsection{The Cultural TV Debate}

The emphasis on the existing capacities reflects the insistence on the signifier of values in cultural debates, which is frequently used by the hardliners in their discourses. This emphasis is due to the fact that the signifier of values is a concealed and subjective concept. Therefore, unraveling it is rather based on the concealed issues than the objective ones, and its realization depends on being discovered rather than taking action, programming and law enforcement. That is the reason why Saeed Jalili does constantly resort to the floating signifier of value to foreground the nodal point of values. The term "value" frequently appears in Jalili's debates to approve of the status quo while using it as an ideal image for the future. He stresses this issue in his cultural TV debates:

We should identify the high capacities of the Islamic culture,... we have some capacities in the cultural arena, including the sacred defense culture which is one of our sources of pride, and we have to use these capacities.

Thereby, whenever Jalili stresses the importance of capacity, he does it to hide the shortcomings of the status quo. He does not recognize these shortcomings as an outcome of subjectivism and values, but as a result of them not being discovered yet. He also mentions capacities to accentuate the importance of values and to foreground them. In fact, by the term "capacities" he means sacred defense, leadership, Islam, and the political system.

Or in other place Jalili says:

One of the essential debates, which is a special duty of the state, is to reduce pressures and to open the chains in order to free the capacities. The Islamic Revolution was an invasion against the western culture. We are in an active position, not a passive one. The fact that they have established 100 satellite TV channels, is a response to our might, and of course they have not been successful. This indicates the strength of our culture, on condition that we can use it properly, and utilize all the capacities. Today some people create monopoly; they have formed aristocracy in the cultural domain, and claim they are the only ones who should talk in this field. They have fiercely attacked any person who has dared to talk, of course by cultural means, not by the means of police force. This monopoly prevents the capacities from being realized...We talk about two newspapers being closed down, but we do not say anything about the [human] capacities in the rural areas which can never use the opportunities. What percentage of the media are now available to what capacity of the society? A major portion of these capacities are underprivileged. Why do we have narrow political views? We say if a particular political drive is free we have freedom; and if it is not, shall we say there is no freedom?

Jalili sees the capacities as the only real element that could tackle the threats, and the only driving force. At the same time, he tries to place the signifier of capacity against the signifier of aristocracy in order to foreground it. While he links the others' discourse to aristocracy, he tries to define the signifier of capacity in a way that it is placed against the signifier of aristocracy.

Simple lifestyle is another one of those floating signifiers in cultural debates, which has been there in the discourse of Islamic republic since the beginning of the Islamic revolution. It has always been invoked by political groups, for it has been a source of power for mobilizing the oppressed people. However, during the period of economic developments (Executives of Construction Party) and political reforms (Reform Movement) this signifier was, to some extent, left aside since it was not in harmony with the economic regulation policies. But Ahmadinejad employed it in 2005 elections, and could win an unexpected landslide victory by placing it against the signifier of aristocracy. The important issue here is the way this signifier becomes hegemonic in relation to the way it is expressed. Jalili's calm and academic tone was not in harmony with Ahmadinejad's radical tone and populism, and as a consequence, this signifier did not become hegemonic, whereas the opponents' discourse relied on the experiences of Ahmadinejad administration to turn it into Jalili's Achilles heel. For instance, Jalili contends, "One should look at the culture that is infused by the government officials; is it aristocracy or simple lifestyle? Justice or discrimination?". By placing these two signifiers together, he both magnifies the simple lifestyle and ascribes it to the opposite 
one. In this way, he questions the moderates' signifier of law-abidingness, implying that the law could be observed only when it is based on beliefs and capacities. However, in their discourse the opponents referred to the experiences from eight years of Ahmadinejad administration to employ the same signifier in the opposite way. They tried to show that any person who emphasizes the signifier of simple lifestyle is, in fact, attempting to deceive people and bypass the law, for he ignores the law by considering it subordinate to the capacities. In the cultural debate Rouhani says:

When the policies are established by the state, and the law becomes transparent, the solution is to hand over many of the responsibilities to the professional institutes and the union system...morality had been there before the revolution as well, and the people are Muslim and they have moral values. But, are we in a good position now? You are right to say that there should not be any aristocratic culture. There should not be any prodigality. But, where did those who boasted of simple lifestyle end up? Those who talked about tackling corruption. See where the Rls.3,000,000,000 corruption came from. If we do not want to have any corruption we must respect the freedom of media and the press.

As a matter of fact, Rouhani uses the signifiers of law, transparency, and free media, to deconstruct the signifier of simple lifestyle, and excludes it using the other signifiers such as guardianship and corruption. He foregrounds the signifier of law, while portraying the signifier of simple lifestyle as something superficial that is meant to deceive people and hide the corruption. That is due to the fact that the emphasis on simple lifestyle and the exclusion of luxurious lifestyle, are all about partisan politics. They are intended to mobilize the masses and stir their feelings in order to evade the law.

\section{CONCLUSION}

As indicated in this research, neither of the two extremist and moderate groups have been able to offer a correct articulation of their discourses. Based on the logic of discourse, they mostly presented themselves within the framework of defensive discourse, rather than an actual discourse. However, the critical condition of the Iranian economy and the offensive foreign policy had led to a situation in which the two major signifiers of value and key were placed face to face with each other, and each of them relied on its own nodal point to blame the other one for all the problems. In this situation, the extremist discourse did still insist that the country's atmosphere is calm and ideal, and if there is any problem, it is because of the departure from principles and values. The other group believed that the difficulties are due to the authorities' disregard for the signifiers of key, solution, and contrivance, and this attitude has especially been formed by blind and reckless insistence on the values, and the desire to see everything as either black or white. Both groups have applied some methods to foreground themselves and exclude the other. But in reality, both camps lacked the instruments of discourse. They only relied on nodal points to attract public votes, and had assumed the role of criticizers using defensive discourse. Therefore, the victory of the "contrivance and hope" administration, and its success in attracting a large percentage of the voters, was not an outcome of articulation, but that of excluding the other side and highlighting the grandeur of the "key". This method appeared to be a very natural strategy in a crisis situation. The country was struggling with a crippled economy which was caused by the performance of the former administration. The economy was based on Islamic economy and the concept of justice, and tried to draw people's attention by such populist slogans as "bringing the oil money to the dining tables". The country's foreign policy and the international sanctions were also among the major causes of the subsequent economic crisis. This situation made the discourses more than ever floating. It prepared the election rivals for a fierce power struggle and prompted them to produce new discourses that were different from the former discourses. Therefore, the winner of the election would be someone who excludes extremism. Any discourse that is able to activate its nodal point, and distinguishes itself from that of the former administration, will have a chance of winning public approval. In this respect, the "contrivance and hope" administration tried to show that it is very close to the Reformists and Executives of Construction, with the goal of producing a discourse of its own. However, the floating nature of such discourses as contrivance, hope, rationality, avoiding 
extremism, promoting proficiency, searching for scientific solutions etc. indicates that this new administration has not been able to make its theoretical system hegemonic, and its discourse is mostly based on the exclusion of others. For a better assessment of this problem, a number of examples from the cultural, economic and political TV debates were brought here to show that the metaphorical atmosphere did only temporarily turn the floating signifiers into "elements", so that it can also convert them into "moment" and make them hegemonic, and in this way it managed to win the 2013 presidential election.

\section{References}

[1] Bashiriyeh, H. (1998). Civil Society and Political Development in Iran. Tehran: Novin Press.

[2] Dabir Mehr. A and M. Tabatabai Fatmi (2014). Laclau and Mouffe's Theory of Discourse in Novel Applied Siences, 3(11): 1283-1287.

[3] Dabiri Mehr. A. (2013). Cutural Components of the Islamic Resistance Discourse in the Middle East, Institute of Culture, Arts and Communication.

[4] Iran Nejad, I. (2012). The Islamic Reformist Discourse in the Post-Revolution Iran. Tehran: Amir Kabir press.

[5] Iranian Channel One (Producer), 2013. May 31. Presidential debate on Economy (Television Broadcast), IRIB, Iran.

[6] Iranian Channel One (Producer), 2013. June 5. Presidential debate on Politics (Television Broadcast), IRIB, Iran.

[7] Iranian Channel One (Producer), 2013. June 7. Presidential debate on Culture (Television Broadcast), IRIB, Iran.

[8] Laclau, E. and Mouffe, C.(1985). Hegemony and Socialist Strategy: Towards a Radical Democratic Politics. London: Verso.

[9] Soltani, Ali-Asghar (2005) Power, Discourse and Language: The Mechanisms of Power in the Islamic Republic of Iran. Tehran: Nashreney Pub.

[10] Stephen, R. C. Hicks. (2013). Explaining Postmodernism: Skepticism and Socialism from Rousseau to Foucault, Persian translation by H.P. Safir, Khatereh Zohrabi, and Farzaneh Ehsani. Tehran: Goqnoos publication. 